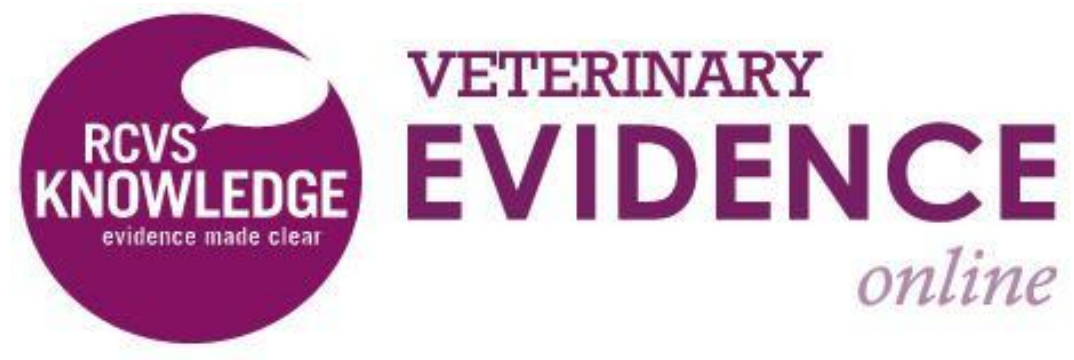

\title{
The Evidence Base for Developing a Veterinary Business Management Curriculum
}

Elizabeth L. Jackson BAg (Hons) MBA PhD SFHEA ${ }^{1^{*}}$

Sarah Hauser BSC (Hons) MPA MPP ${ }^{1}$

${ }^{1}$ Royal Veterinary College, Hawkshead Lane, North Mymms, Hatfield, Hertfordshire, AL9 7TA, United Kingdom

Corresponding Author (eljackson@rvc.ac.uk)

ISSN: 2396-9776

Published: 02 June 2016

in: Vol 1, Issue 2

DOI: http://dx.doi.org/10.18849/ve.v1i2.38

Reviewed by: Hannah Perrin (BSc MA PGCHE PGDipHE FHEA PhD) 
Objective: This paper sets out to highlight the ongoing need for integrated teaching of business skills in the veterinary curriculum.

Background: In response to the changing environment of the veterinary profession, it is important to understand the future needs of veterinary practitioners. While changes to the veterinary curriculum have been made in recent years, they have been highly varied across schools and little evidence is available on how these have improved students' non-technical skills, knowledge, aptitudes, and attitudes.

Evidentiary value: This literature review of 23 papers provides a solid basis for the further development of knowledge on business management issues in veterinary curricula. The impact on practice from our findings is substantial. The role of clinicians in academia is recognised as a primary source of engaging students with business management through their day-to-day teaching. Furthermore, the role of first-opinion vets who take on placement students (known as extra mural studies or 'EMS' in the UK) cannot be underestimated as they play an essential role in ensuring that students perceive business skills with the same importance as clinical skills.

Methods: This research draws on the findings of 23 papers that emerged as relevant from the structured literature search. The search yielded 124 papers but many were excluded because they focused on issues beyond the search strategy, did not report empirical findings so were based largely on discussion and conjecture, were not about the undergraduate veterinary curriculum, were not written in English or were not related to business teaching.

Results: Employers of recent graduates highly value business skills, and often base their hiring decision on non-technical skills, rather than clinical skills. While changes to the veterinary curriculum have been made to include more non-technical training by individual veterinary schools, it is unclear how effective these programmes have been.

Conclusion: Veterinarians have identified a need for greater inclusion of business skills in the veterinary curriculum, however successfully integrating business skills into the curriculum will mean that students learn business principles in non-traditional, non-lecture-style environments with materials inter-twining with clinical teaching. This will mean a significant shift from traditional classroom based delivery of business lectures to an integrated approach. This can only be achieved if business and clinical teaching staff work together in delivering business education to the next generation of veterinarians. That said, the evidence regarding the importance of business within the veterinary medical curriculum, coupled with increasing competition in the market for first-opinion veterinary services, means that changes in the approach to teaching business may be easier to achieve than ever before.

Application: The results of this research are applicable to practicing veterinarians in both academic and private practice. It is clear that business management needs to be integrated throughout the veterinary curriculum and thus 'owned' by academics with both clinical and non-clinical roles. Veterinarians in private practice also have a critical role to play as these people are the gatekeepers to the real-world experience that placement students encounter.

\section{INTRODUCTION}

In response to the changing environment of the US veterinary profession, significant advancements were made in understanding the future needs of the veterinary profession by Brown and Silverman (1999). One of the resounding findings, later supported by Volk et al. (2011) and Harris and Lloyd (2011), was related to the 
skills, knowledge, aptitude and attitude of vets in terms of business, management and communication skills. The qualitative phase of Harris and Lloyd's (2011) research showed that their research participants were not prepared for the management requirements of private practice and that they did not receive enough training in management, communications and other skills necessary for non-private practice. In terms of veterinary graduates being able to fulfil roles beyond the practice, it was found that vets would be in a better position to fill non-clinical roles if they had better training in speaking/writing, business, administration, personnel management, sales/marketing, finance and computing. Volk et al. (2011) went on to identify eight business practices as the leading predictors of higher personal income: business orientation, frequency of financial data review, employee development, negotiating skills, client loyalty, leadership, client retention and new client development. An important caveat to this list is that it is applicable to all types of vets (i.e. companion animal, equine, food animal and mixed-practice).

Lloyd et al. (2007) further developed the work of Brown and Silverman (1999) with an emphasis on the importance of leadership skills for vets. Their findings highlighted the important role veterinary medical schools and faculties play in providing a pool of candidates for future tertiary administrators of the profession. They espouse that funding for leadership development programmes should be part of every veterinary education institution's budget. Similarly, Hodgson et al. (2013) identified leadership as one of the nine essential competencies for veterinary graduates and, like Lloyd et al. (2007), recommended the inclusion of this skill in veterinary curricula. Even more recently, Henry and Jackson (2015) recognised the imbalance of leadership roles held by women in the UK veterinary profession. They posited the importance of leadership training for women in the face of their dominance in the profession and warned of the profession being led by people unrepresentative of its major demographic.

In terms of preparing vets to deal with erratic changes in the economic climate and ensure their businesses are resilient enough to cope with the ebbs and flows of clients' incomes, Volk et al. (2011) concur with the findings of Bachynsky et al. (2013) and Brown and Silverman (1999). They suggest three factors that would make it more likely for vets to be visited more often - all are related to business and none are related to clinical skills: more predictability in the cost of veterinary care, competitive prices for products available through competing channels (e.g. dietary supplements and parasite control products) and improved convenience of the service offering by extending opening hours and pet drop-off appointments.

Harris and Lloyd (2011) recognise the substantial changes that have been made to veterinary curricula in the USA since the publication of Brown and Silverman's (1999) work. They identified increases in communications training and more, but highly-varied, options to improve their students' non-technical skills, knowledge, aptitudes, and attitudes. However, the question remained regarding the effectiveness of these changes to curricula and how they have been converted into graduates who possess skills for economic success. On the other hand, Hodgson et al. (2013) have the opinion that veterinary schools are lagging behind their practitioner colleagues in grasping the importance of skills in personnel management, business management and leadership. These authors report on "a recent survey of [North American] faculty regarding the teaching of professional competencies almost half the faculty respondents did not perceive a responsibility to teach or assess business skills." (Hodgson et al., 2013, p. 110). In addition, Volket al. (2011) drew two alarming conclusions in relation to the uptake of business practices amongst vets. They found that, irrespective of the numerous opportunities to improve performance, there is a low use of widely-accepted business practice amongst vets. Despite annual incomes increasing substantially, companion animal vets did not increase their use of 19 standard business practices. The conclusion was that results point to the fact that incomes were 
increasing due to the unsustainable practice of increasing fees rather than other improvements to business knowledge.

Veterinarians are often not adequately prepared for the management requirements of private practice due to a lack of training in management, communications and other non-clinical skills. There is a need to understand what makes veterinarians more prepared to deal with changes in the economic climate and ensure their businesses are resilient enough to cope with the ebbs and flows of clients' incomes.

State hypotheses: As this is a literature review determining the evidence base for developing a veterinary business management curriculum, a statement of hypothesis is not relevant.

\section{METHODS \& MATERIALS}

This research reports on the results of a structured literature review. The Royal Veterinary College's SCOut database was used to search for papers. This search engine simultaneously searches the following databases: BioMed Central Journals, BioOne, British Library Public Catalogue, CAB Direct, CABI AHPC, Animal Health and Production Compendium, Cochrane Library, Compendium on Continuing Education for the Practicing Veterinarian, Copac National, Academic, and Specialist Library Catalogue, Consultant Veterinary Diagnostic Database, DEFRA, Directory of Open Access Journals (DOAJ), EThOS, Internet Center for Wildlife Damage Management, IVIS: International Veterinary Information Service, National Institutes of Health (NIH), NOAH Datasheets, Pubmed, ResearchGate Scientific Network, ScienceDirect, Springer Protocols, SUNCAT, Veterinary Information Network (VIN), Veterinary Medicine, Veterinary Practice News, VetnetBase, Vetsonline, Vetstream, Web of Science, Wellcome Library, WikiVet, Wildpro, Wiley Online Library, Zetoc Electronic Table of Contents. After some trial and error, the following search terms were used to search the database:

veterinar* AND business* AND (educat* OR curricul*)

It should be noted that this literature review does not include published commentaries on the subject of integrating business into the veterinary medical curriculum. As these pieces were based on opinion and conjecture, they were excluded from the analysis.

Research into integrating business skills in veterinary medical curricula is approached in disparate fashions to include methodological approaches that span inductive approaches whereby conclusions are drawn from thematic coding of focus group data (e.g. Lloyd et al., 2005) to deductive research where logistic regression is used to analyse survey data (e.g. Adam et al., 2015). As such, sample sizes for research considered in this review vary considerably. A lot of published research also consists of literature reviews on the topic and therefore offer opportunities for further exploration, rather than definitive conclusions based on empirical research.

\section{RESULTS}

\section{A high demand for non-technical skills among the veterinary community}

Many veterinary practitioners are aware that clients do not choose a veterinarian based on his or her clinical skills and knowledge alone. In many cases clients are not aware of these skills and cannot judge them adequately, instead the veterinarian-client relationship, and as a result client trust and client retention is built 
through non-technical skills. Employers of veterinarians are now looking for more than a sound clinical background. Non-technical veterinary skills significantly contribute to employer satisfaction, as is found by Danielson et al. (2012). Non-technical skills assessed in their survey included interpersonal-skills, making referrals, ability to deal with legal issues, business skills and problem solving. The three skills most significantly correlated to employer satisfaction were found to be: interpersonal skills, business skills and problem solving. While the authors present a clear, statistically significant link, there are limitations to the paper, such as small sample size and the sample being only graduates of the lowa State University College of Veterinary Medicine. In addition, the term "business skills" is not clearly defined, and no conclusion can be drawn about what kind of business skills employers value. When answering the survey employers could have had a number of business related skills in mind, such as practice management, time management, effective handling of administrative tasks, or something else entirely. This issue is partially addressed by Butler (2003), in a survey of employers and new graduates where the term business skills is broken into conflict management skills, time management, financial management, file management, retrieving, compiling and analysing data, professional writing skills, presentation and public speaking skills and awareness of public concerns challenging business/industry's future. These skills were perceived differently by employers and employees, which is an interesting outcome in itself, and leads to the question on what graduates' expectations of the workplace look like. However, the author fails to analyse or comment on the results in more detail and shed light on the consequences of these findings.

Bachynsky et al. (2013) were the most recent authors to publish work on the business skills of veterinary practitioners. Their research focused on opinions of recent graduates $(n=150)$ and employers $(n=150)$ and revealed six areas that new graduates should have cognisance: financial performance appraisal, communications to clients of charging and payment, recognising the commercial consequences of undercharging, understanding sources of profit in developing pricing estimates for clinical services and equipment investment decisions. While these factors were statistically significant, evidence is lacking in regards to the breadth of employees contributing to the study (i.e. were they only veterinary practices or were a broader range of employers considered e.g. corporate practices, government agencies, abattoirs, Official Veterinarians (OVs)?) and the source of the questions (i.e. were the right questions being asked? What evidence is there to suggest that the questions contributing to this survey were well-founded and discipline-specific?).

\section{The emphasis on communication}

It is widely accepted by the veterinary profession, that veterinary medicine is more than treating animals. One of the most important skills to have as a veterinarian is the ability to communicate and effectively share information and knowledge with clients, the public and colleagues. This was also found in a study by Rhind et al. (2011) where most final year students $(n=161)$ and recent graduates $(n=90)$ ranked communication skills with clients and the public followed by communication skills with colleagues as 'very important'. Despite significant advances being made in the education of veterinary students in client communications, this theme still features strongly as a non-technical competency that needs to be included in veterinary medical education. It is mostly discussed in papers published in the early 2000s but the need to improve client communications remains a key non-technical competency addressed by the literature. In a survey of recent graduates and senior partners Routly et al. (2002) found that, in addition to more practical experience, many senior veterinarians listed a greater commitment in undergraduate training to financial/legal skills and communication skills. This sentiment was echoed by the recent graduates surveyed.

Non-clinical skills as a path to employment 
Non-clinical skills are valued highly by employers of veterinarians, who often choose their employees from a pool of graduates with a very similar level of clinical skills. While in-theory grades and academic performance may feature in employers' decision making, Roth et al. (2014) found that when examining factors that influence students' average transactions in a small-animal primary care clinical environment, that there is no statistically significant correlation between grades and class rank and economic performance. This finding is supported by Routly et al. (2002), stating that selection during job interviews is often based on personality and communication skills and a perceived empathy for the job. A basic clinical prowess is expected by the fact that the student graduated and, in the UK, is thus a Member of the Royal College of Veterinary Surgeons. These findings highlight the need for students and academic institutions to provide classes on business and communication skills. A limitation of the Roth et al. (2014) paper is that purely average client transaction was measured rather than also measuring client satisfaction and retention. This is grounds for further research as it has been shown that through client communication, involving clients in the decision making process and getting client buy-in, this can alleviate some of the financial challenges involved in veterinary-client interactions (Coe et al, 2009).

\section{Including business skills in the veterinary curriculum}

A search of the literature highlights that the early 2000s were a turning-point in teaching veterinarians some business skills. Numerous studies show that veterinarians need a strong background in business skills such as practice and financial management, in order to achieve commercial success (Kogan et al., 2005; Jaarsma et al., 2008; Lloyd and Covert, 2001).

There is mixed evidence concerning students' and graduates' attitudes towards business education. When compared to clinical subjects, business or commercial education were not a priority for students of veterinary medicine, when however, employers were asked, business acumen and good communication skills were some of their top priorities. Findings from student and recent graduate surveys show that students find clinical subjects to be more important for their career than business management skills (Rhind et al., 2011) and, the teaching of practice and business management is one of the top underrepresented non-clinical topics in the veterinary curriculum. Veterinarians however are concerned that they do not receive enough training in practice management and client communication, as well as working independently and practical/technical skills, during their time at university (Jaarsma et al., 2008).

When veterinary students were specifically asked about their interest in non-clinical subjects, Kogan et al. (2005) showed that there are high levels of interest in the subjects of veterinary practice management and the fundamentals of management. These authors purely focus on ranking classes related to business management among veterinary students, they do not compare these to other (technical skills), whereas Rhind et al. (2011) asked final year students and recent graduates which skills are considered to be 'very important'. In follow-up interviews and focus groups the same study presents results suggesting the ranking of business acumen and knowledge of veterinary practice management should be higher. This suggests that business skills are perhaps not prominent in the minds of new clinicians, but they acknowledge that when advancing in the veterinary profession, they become more important. The limitations of these studies are that they represent the views of the students and employees, thus does not represent the skills employers value. Furthermore, first year graduates are likely to be employees rather than being in practice management positions. Repeating the survey after five or even 10 years in practice could provide a very different survey outcome. 
Another key theme, highlighted by Lloyd and Covert (2001), is the way business education is taught in veterinary schools in the US. It was found that a wide variety of course topics, such as marketing, personnel management, financial management, law and ethics and personal management were being taught, however there was very little agreement between schools about where the focus of veterinary practice management (VPM) courses should lie. It was highlighted that graduates from two different schools, despite both having to take at least one VPM module, could have very different learning outcomes. The authors suggest that educational priorities in practice management should be set from the perspective of experts in the field, that an outcomes assessment should be undertaken and that initiation of academic research programs in VPM should be initiated to provide a knowledge base for future educational programs.

The approach of Lloyd and Covert (2001) assesses VPM as an 'add on' subject, rather than part of an integrated approach as advocated by Henry and Jackson (2015) and Poon et al. (2014). These authors suggest that there is substantial evidence to support the importance of integrating, rather than inserting, business skills into the veterinary medical curriculum. A number of methods to achieve this ambition have been outlined herein: teach business skills via student experiences in veterinary hospitals (Poon et al., 2014) and ensure all teaching staff are sufficiently trained to mentor students and impart knowledge of non-technical competencies (including business) with students as-and-when required (Lane and Bogue, 2010).

Lane and Bogue (2010) also highlight that while veterinary faculty share responsibility of teaching critical thinking skills, ethics, communications skills and interpersonal skills, almost half the faculty respondents did not perceive a responsibility to teach business skills. The interpretation of these results are twofold, on the one hand it could suggest that business skills are being taught by business lecturers and designated faculty members, and so others do not see the need to integrate these skills in their subjects, or it could be that business skills are not being prioritised within the curriculum. It does however clearly show that the approach taken by Poon et al. (2014) to integrate business skills is unlikely to be the reality of business teaching.

\section{Education beyond the classroom}

Once in employment, Adam et al. (2015) found that in order to retain farm animal veterinarians in practice, the following strategies need to be implemented in business: regular staff appraisals, having the support of an experienced veterinarian, especially in on-call situations, and improve job satisfaction amongst the new employees by better training and support of practice management staff. It is unclear if these findings are applicable to all veterinary practitioners, or if they are specific to farm animal veterinarians.

Similarly Lloyd et al. (2005) suggest that cross training, staff development and other benefits, such as discounted animal health care are important factors of staff satisfaction of a veterinary teaching hospital. In the quest to develop a standardised business model for veterinary teaching hospitals the following key themes were identified: operationalising the mission, financial management, HR management, pricing, marketing, operations, legal and ethical issues and constraints to success.

Finally, some literature takes a broader view on business skills, than pure financial and client management, it takes into account emotional intelligence (Timmis, 2006; Lane 2010). This is often included as non-technical competencies, along with communication skills. Timmins (2006) highlights the importance of emotional 
intelligence in veterinary medical education, especially for the field of companion animal medicine, with $85 \%$ of pet owners viewing their pet as a family member, with emotional intelligence potentially improving client satisfaction and compliance with therapy.

DISCUSSION

This paper is a literature review of evidence for the development of a veterinary business management curriculum. It has described the evolution of business management in the veterinary curriculum and highlighted six key themes for curriculum managers to be aware of:

- A high demand for non-technical skills among the veterinary community

- The emphasis on communication

- Non-clinical skills as a path to employment

- Including business skills in the veterinary curriculum

- Improving the way business skills are taught in vet schools

- Education beyond the classroom

Perhaps a less-obvious theme to emerge from this work is the importance of first-opinion practitioners in shaping the views of future veterinarians in accepting business management education. Evidence suggests that first-opinion practitioners strongly support the integration and business management into the veterinary curriculum but undergraduate students need encouragement to engage with this learning. While the literature is abundantly clear on the importance of veterinary business education, few clues exist of how to operationalise this within the curriculum. As a result, there is much scope for further investigation of this matter.

The major limitation of this research is the paucity of recent, empirical findings on which to build an evidence base for developing a veterinary business management curriculum. The structured literature search yielded numerous commentaries published in leading veterinary journals, such as the Vet Record, however these pieces were rarely based on empirical evidence, rather they were based on experience, opinion and conjecture. Such papers may be an easy-read for practitioners and help them to engage in business issues but they are not helpful in developing an evidence base to draw upon for well-structured, well-researched guidance.

A further limitation is the absence of research about the advent of corporate veterinary practices in the UK. In 1998, legislation changed to allow non-vets to own veterinary practices. This change eventuated in an explosion of corporate veterinary businesses, which are often characterised as being run by people with acute business skills, rather than the traditional veterinary clinical skills. The consequence is that competition has increased with independent veterinary businesses finding it difficult to compete against commercially-savvy businesses that focus on cost-reduction, client relationship management, supply chain efficiency and overall systems optimisation. As with much of the literature on veterinary business management, there is a lot written about managing competition but we were not able to identify any empirical evidence. The final limitation to recognize herein is the omission of knowledge gained from the animal health economics literature. There are numerous overlaps between economics and business skills such as tools for optimising investment and decision making. This was recently highlighted by Jackson et al. (2015) who reported on findings from the NEAT project (see: http://www.neat-network.eu/). These findings largely concur with the findings of the present literature review: that animal health economics (which includes using economics for general business management and understanding markets) needs to be better embedded into global veterinary curricula.

To conclude, there is plenty of convincing evidence to suggest that veterinarians have identified a need for greater and more effective inclusion of business skills in the veterinary medical curriculum. However there are 
disparate opinions about what the term 'business skills' truly means. The consequence of this is that the fundamental requirements of establishing business teaching within a veterinary medical curriculum remain sketchy. Evidence points to the idea that successfully integrating business skills into the veterinary medical curriculum will mean that students learn business principles in non-traditional, non-lecture-style environments with materials inter-twining with clinical teaching. This will mean a significant shift in the delivery of teaching materials and will need a great deal of acceptance from clinical teaching staff. That said, the evidence regarding the importance of business within the veterinary medical curriculum, coupled with increasing competition in the market for first-opinion veterinary services, means that changes in the approach to teaching business may be easier to achieve than ever before.

\section{CONFLICT OF INTEREST}

The authors declare no conflicts of interest.

\section{REFERENCES}

1. Adam, K. Baillie, S. and Rushton, J. (2015) Retaining vets in farm animal practice: a cross-sectional study. The Veterinary Record, 176 (25), pp. 655. http://dx.doi.org/10.1136/vr.103170

2. Bachynsky, E.A. et al. (2013) A survey of the opinions of recent veterinary graduates and employers regarding early career business skills. The Veterinary Record, 172 (23), pp. 604. http://dx.doi.org/10.1136/vr.101376

3. Brown, J.P. and Silverman, J.D. (1999) The current and future market for veterinarians and veterinary medical services in the United States. Journal of the American Veterinary Medical Association, 215 (2), pp. 161-183.

4. Butler, D. G. (2003) Employer and new graduate satisfaction with new graduate performance in the workplace within the first year following convocation from the Ontario Veterinary College. The Canadian Veterinary Journal, 44 (5), pp. 380-391.

5. Coe, J.B. Adams, C.L. and Bonnett, B.N. (2009) Prevalence and nature of cost discussions during clinical appointments in companion animal practice. Journal of the American Veterinary Medical Association. 234 (11), pp. 1418-24. http://dx.doi.org/10.2460/javma.234.11.1418

6. Danielson, J. A. et al. (2012) Predictors of employer satisfaction: technical and non-technical skills. Journal of Veterinary Medical Education, 39 (1), pp. 62-70.

http://dx.doi.org/10.3138/jvme.0711.072R

7. Harris, D.L. and Lloyd, J.W. (2011) Changes in teaching of nontechnical skills, knowledge, aptitudes, and attitudes at US colleges and schools of veterinary medicine between 1999 and 2009. Journal of the American Veterinary Medical Association, 239 (6), pp. 762-766.

http://dx.doi.org/10.2460/javma.239.6.762

8. Henry, C. and Jackson, E. L. (2015) Women's entrepreneurship and the future of the veterinary profession, e-Organisations and People, 22 (3), pp. 34-42.

9. Hodgson, J.L. Pelzer, J.M. and Inzana, K.D. (2013) Beyond NAVMEC: competency-based veterinary education and assessment of the professional competencies. Journal of Veterinary Medical Education, 40 (2), pp. 102-118. http://dx.doi.org/10.3138/jvme.1012-092R

10. Jaarsma, D. A. et al. (2008) Preparation for practice by veterinary school: a comparison of the perceptions of alumni from a traditional and an innovative veterinary curriculum. Journal of Veterinary Medical Education, 35 (3), pp. 431-438. http://dx.doi.org/10.3138/jvme.35.3.431 
11. Jackson, E. L. et al. (2015) Europe Needs Consistent Teaching of the Economics of Animal Health. EuroChoices, 15 (2), pp. 42-49. http://dx.doi.org/10.1111/1746-692X.12098

12. Kogan, L. R. McConnell, S. L. and Schoenfeld-Tacher, R. (2005) Response of a veterinary college to career development needs identified in the KPMG LLP study and the executive summary of the Brakke study: a combined MBA/DVM program, business certificate program, and curricular modifications. Journal of the American Veterinary Medical Association, 226 (7), pp. 10701076.http://dx.doi.org/10.2460/javma.2005.226.1070

13. Lane, I. F. (2010) Professional competencies in health sciences education: from multiple intelligences to the clinic floor. Advances in Health Sciences Education, 15 (1), pp. 129-146. http://dx.doi.org/10.1007/s10459-009-9172-4

14. Lane, I. F. and Bogue, E. G. (2010) Perceptions of veterinary faculty members regarding their responsibility and preparation to teach non-technical competencies. Journal of Veterinary Medical Education, 37 (3), pp. 238-247. http://dx.doi.org/10.3138/jvme.37.3.238

15. Lloyd, J. W. and Covert, B. R. (2001) Veterinary practice management education in the Association of American Veterinary Medical Colleges member colleges during 1999. Journal of the American Veterinary Medical Association, 219 (2), pp. 176-179. http://dx.doi.org/10.2460/javma.2001.219.176

16. Lloyd, J. W. Harris, D. L. and Marrinan, M. J. (2005) Development of a veterinary teaching hospital business model. Journal of the American Veterinary Medical Association, 226 (5), pp. 705710.http://dx.doi.org/10.2460/javma.2005.226.705

17. Lloyd, J.W. et al. (2007) Enhancing nontechnical skills, knowledge, aptitudes, and attitudes through veterinary leadership development programs. Journal of the American Veterinary Medical Association, 230 (10), pp. 1481-1485. http://dx.doi.org/10.2460/javma.230.10.1481

18. Poon, W. L. et al. (2014) Evaluation of a Primary-Care Setting at a Veterinary Teaching Hospital by a Student Business Group: Implementing Business Training Within the Curriculum. Journal of Veterinary Medical Education, 41 (2), pp. 189-196. http://dx.doi.org/10.3138/jvme.0913-130R

19. Rhind, S. M. (2011) The transition into veterinary practice: opinions of recent graduates and final year students. BMC Medical Education, 11 (1), pp. 64-74. http://dx.doi.org/10.1186/1472-6920-11-64

20. Roth, I. G. Poon, W. L. and Hofmeister, E. (2014) Examination of Factors That Influence Students' Average Client Transactions in a Small-Animal Primary Care Clinical Environment. Journal of Veterinary Medical Education, 41 (4), pp. 400-405. http://dx.doi.org/10.3138/jvme.0114-003R1

21. Routly, J. E. et al. (2002) Support needs of veterinary surgeons during the first few years of practice: perceptions of recent graduates and senior partners. The Veterinary Record, 150 (6), pp. 167-171. http://dx.doi.org/10.1136/vr.150.6.167

22. Timmins, R. P. (2006) How does emotional intelligence fit into the paradigm of veterinary medical education?. Journal of Veterinary Medical Education, 33 (1), pp. 71-75. http://dx.doi.org/10.3138/ivme.33.1.71

23. Volk, J.O. et al. (2011) Executive summary of the Bayer veterinary care usage study. Veterinary Medicine Today, 238 (10), pp. 1275-1282. http://dx.doi.org/10.2460/javma.238.10.1275 


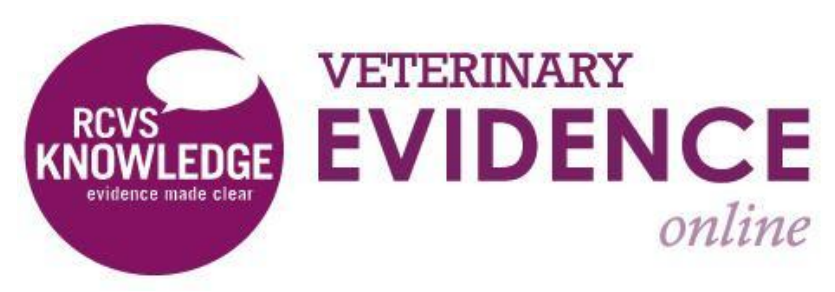

\begin{abstract}
Intellectual Property Rights
Authors of Articles submitted to RCVS Knowledge for publication will retain copyright in their work, but will be required to grant to RCVS Knowledge an exclusive license of the rights of copyright in the materials including but not limited to the right to publish, re-publish, transmit, sell, distribute and otherwise use the materials in all languages and all media throughout the world, and to license or permit others to do
\end{abstract} so.

Authors will be required to complete a license for publication form, and will in return retain certain rights as detailed on the form.

Veterinary Evidence and EBVM Network are RCVS Knowledge initiatives. For more information please contact us at editor@veterinaryevidence.org.

RCVS Knowledge is the independent charity associated with the Royal College of Veterinary Surgeons (RCVS). Our ambition is to become a global intermediary for evidence based veterinary knowledge by providing access to information that is of immediate value to practicing veterinary professionals and directly contributes to evidence based clinical decision-making.

www.veterinaryevidence.org

RCVS Knowledge is a registered Charity No. 230886. Registered as a Company limited by guarantee in England and Wales No. 598443.

Registered Office:

Belgravia House

62-64 Horseferry Road London SW1P 2AF

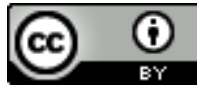

This work is licensed under a Creative Commons Attribution 4.0 International License. 